\title{
Suckling CD1 mice as an animal model for studies of Legionella pneumophila virulence
}

\author{
M. CASTELLANI PASTORIS, E. PROIETTI*, C. MAURI', P. CHIANI and A. CASSONE \\ Laboratories of Bacteriology and Medical Mycology and *Virology, Istituto Superiore di Sanità, Viale Regina \\ Elena, 299-00161 Rome, Italy
}

\begin{abstract}
On the assumption that specific host defences are lower in newborn and infant animals, the susceptibility of CD1 suckling mice to Legionella pneumophila was studied with the hypothesis that this model could detect consistent differences in virulence among Legionella isolates from various clinical and environmental sources. Mice 3-14 days old were indeed markedly susceptible to intraperitoneal challenge with fresh clinical isolates, but not to serially subcultured or type collection strains of $L$. pneumophila. For example, intraperitoneal inoculation of $10^{7}$ cells of a fresh clinical isolate of $L$. pneumophila (strain Monza 3) caused $60 \%$ mortality of suckling mice in 1 day whereas the same number of cells of a culture-attenuated derivative (strain Monza 3p50) caused $<10 \%$ mortality in $>15$ days. Lethal infection by the 'virulent' Monza 3 strain was strictly dependent on mouse age (no death was observed in mice $>26$ days old), required the inoculation of viable cells and was not related to endotoxin production. The 'virulent' $L$. pneumophila strain was cleared from mouse lungs less rapidly, while adhering to, and being internalised into the peritoneal exudate cells (PEC) of suckling mice to a greater extent, than the avirulent derivative, as shown by immunofluorescence and confocal microscopy. The Monza 3 strain also induced the production by PEC in vivo of 5-to-10 times more tumour necrosis factor-alpha (TNF- $\alpha$ ) mRNA than the Monza 3p50 strain. Overall, suckling CD1 mice appear to provide a promising, easily handled, highly reproducible and relatively inexpensive animal model for studies of the virulence of $L$. pneumophila, and possibly, of the role of pro-inflammatory cytokine production in this phenomenon.
\end{abstract}

\section{Introduction}

Legionellae are ubiquitous, facultative intracellular micro-organisms that can cause severe pneumonia in man [1]. In particular, Legionella penumophila is the aetiological agent of Legionnaire's disease [2]. The status of the host's immune system plays a critical role in this disease, as demonstrated by the fact that infection occurs mostly in immunocompromised patients, in patients with underlying diseases and can be induced in immunocompromised experimental animals [3-8]. Nonetheless, legionellae probably possess an array of pathogenicity factors, conferring upon the micro-organisms different degrees of virulence that can be demonstrated by different, complementary in-vivo and in-vitro assays [9-13].

A common in-vivo assay for the evaluation of bacterial virulence is the direct challenge of susceptible animals. Although various animals have been proposed for the assessment of L. pneumophila virulence [13-16], the

Received 10 Oct. 1996; accepted 17 Dec. 1996.

${ }^{\dagger}$ Corresponding author: Dr M. Castellani Pastoris.

Present address: Kennedy Institute of Rheumatology, Department of Immunology, London W6 8LW, UK. most useful appears to be the guinea-pig, either for parenteral or aerosol infection [15]. Normally, adult mice are highly resistant to extensive legionella pneumonia and lethal disease, although not to infection. However, immunocompromised and $\mathrm{A} / \mathrm{J}$ mice have been reported to be more susceptible $[4,7,17-19]$. The proposed models are usually characterised by difficulty in handling and high costs, coupled with inconsistencies and large inter-laboratory variations in the results obtained. To find an easily handled and inexpensive experimental animal model, and on the assumption that specific host defences are lower in newborn animals, the susceptibility of suckling mice to legionellae was studied, with the principal aim of examining whether these animals could be useful in detecting consistent differences in virulence among clinical and environmental isolates of Legionella spp. [20, 21].

\section{Materials and methods}

\section{Micro-organisms}

L. pneumophila strains isolated from patients and from water supplies associated with human infection were used in this study. A few isolates were also serially 
passaged on an artificial culture medium with the aim of selecting avirulent derivatives, one of which, referred to hereafter as Monza 3p50 strain, was reinoculated four times into suckling mice to check for the definitive loss of virulence. The reference strains of L. pneumophila (Philadelphia 1, ATCC 33152), $L$. micdadei Tatlock (ATCC 33218), and L. bozemanii Toronto 3 (ATCC 33545), from type collection cultures, were also used. L. pneumophila strain Corby of known virulence [12] was provided by Dr R. B. Fitzgeorge, CAMR, Porton Down.

Micro-organisms were maintained at $-80^{\circ} \mathrm{C}$ in skimmed milk; after thawing, they were grown at $36^{\circ} \mathrm{C}$ in a humidified atmosphere with $\mathrm{CO}_{2} 2.5 \%$.

\section{Media and reagents}

Buffered charcoal-yeast extract agar containing alphaketoglutarate $0.1 \%$ (BCYE- $\alpha$ agar; Unipath) [22] with and without selective supplement (glycine $3 \mathrm{~g} / \mathrm{L}$, polymyxin B $100000 \mathrm{IU} / \mathrm{L}$, vancomycin $5 \mathrm{mg} / \mathrm{L}$ and cycloheximide $80 \mathrm{ml} / \mathrm{L}$ ) [23] were used as culture media for legionellae.

Subtyping of L. pneumophila serogroup 1 strains was performed according to the Oxford scheme [24] with monoclonal antibodies purchased from the John Radcliffe Hospital, Oxford.

Cells were examined by the direct immunofluorescence (DFA) test with a specific fluorescent antiserum against L. pneumophila serogroup 6 (Scimedx Corporation, NJ, USA).

\section{Preparation of inocula}

After growth for 2-4 days on BCYE- $\alpha$ agar, the microorganisms were suspended in sterile distilled water. Cell concentrations were standardised optically with McFarland density standards and the number of viable organisms contained in the inoculum were counted as cfu.

For some strains, legionellae suspended in water were also killed by heating at $65^{\circ} \mathrm{C}$ for $30 \mathrm{~min}$. In one experiment, bacterial cells were ruptured by sonication of the cell suspension. Cells were then filtered through membrane filters (Millipore, pore size $22 \mu \mathrm{m}$ ) and viable counts were made to calculate the number of disintegrated legionellae by comparison with bacterial counts before sonication.

\section{Endotoxin assay}

The Limulus amoebocyte rapid test (Whittaker Bioproducts Inc.; sensitivity $0.125 \mathrm{ng} / \mathrm{ml}$ ) was performed according to the manufacturer's instructions. Killed legionella suspensions, and cell-free sonicates of the same organisms, were tested to ascertain their endotoxin activity. Sterile pyrogen-free water was used as diluent.

\section{Animals}

Swiss albino CD1 pathogen-free mice (young pregnant females, 2-day-old litters with their mother and young adult males), and Hartley male guinea-pigs weighing $c$. $250 \mathrm{~g}$ were obtained from Nossan or Charles River breeding laboratories, Italy. The animals were housed in individual cages in a laminar flow housing cabinet, with an automatically controlled temperature of $22^{\circ} \mathrm{C}$ and $12 \mathrm{~h}$ of light. Newborn mice were allowed to live with their mother during the experimental period. The mice used were 3-6 days old, unless otherwise stated. The medium weight of a 5-day-old mouse was 3.3$3.5 \mathrm{~g}$.

Mice were killed by exposure to ether or by cervical dislocation.

\section{Experimental model}

The suckling mice were inoculated intraperitoneally (i.p.) with 10 and $20 \mu 1$ of cell suspensions by the use of a Hamilton syringe. Intranasal (i.n.) challenge was also performed by depositing $5 \mu \mathrm{l}$ of the legionella suspension with a micropipette on the external nares of unanaesthetised mice. Deaths were recorded for up to 1 month in the initial experiments, thereafter up to 15 days, and monitored as median survival time (MST, expressed in days) and number of dead over total (D/T) animals. Each experiment was repeated at least three times with different litters. In some experiments, heatkilled legionellae $\left(80^{\circ} \mathrm{C}, 30 \mathrm{~min}\right)$ were used, while in others cell-free sonicates (corresponding to a dose of $(2.5-3) \times 10^{8}$ legionellae) of a freshly isolated strain of human origin, were injected i.p. into mice.

To assess the clearance of $L$. pneumophila from the whole body or internal mouse organs, mice were killed at different days $(2-5)$ post-infection and the contents of the thoracic and abdominal cavities, with the exception of the stomach and the bowel, were removed aseptically together with a peritoneal wash, and homogenised with sterile distilled water. Legionella colony counts were done in duplicate on BCYE$\alpha$ agar after serial dilutions. In other experiments, lung, spleen and liver were removed aseptically, rinsed twice in gentamicin $50 \mu \mathrm{g} / \mathrm{ml}$ solution, and allowed to remain for a further $1 \mathrm{~h}$ in gentamicin at room temperature, to kill the external legionellae. After rinsing twice with sterile distilled water, the organs were carefully homogenised in a mortar and vortex mixed. Serial dilutions were plated and colonies were counted. Guinea-pigs were also used to check the mortality after i.p. inoculation of a human fresh $L$. pneumophila isolate and its culture-passaged derivative. For this purpose, groups of four animals were inoculated i.p. with $1 \mathrm{ml}$ suspensions of $c .10^{7}, 10^{8}$ and $10^{9}$ legionellae from the Monza 3 and the Monza 3 p50 strains, and any deaths were recorded up to 1 month. 
Mouse age-dependent susceptibility to L. pneumophila

To evaluate the dependency on mouse age of the outcome of L. pneumophila infections, groups of eight mice aged $3-16,17-19,20-26$ and $>26$ days were inoculated with $6.5 \times 10^{7}$ legionellae from a suspension of L. pneumophila Monza 3 strain. Mortality was recorded for 15 days, and the MST calculated.

\section{Resident peritoneal exudate cells}

Resident peritoneal exudate cells (PEC) were obtained by washing the peritoneal cavity of infected or uninfected mice with $200 \mu$ l (suckling mice) or $3 \mathrm{ml}$ (adult mice) of RPMI 1640 tissue culture medium (Microbiological Associates Bioproducts, Walkersville, MD, USA). During harvesting the cells were kept in an ice bath to prevent clumping. A small sample was mixed with trypan blue dye solution to check viability, and cells were counted with a haemocytometer. The PEC population was mostly composed of macrophages $(\mathrm{M} \phi)$ and lymphocytes, the former amounting to $>50 \%$, as assessed morphologically. To count $L$. pneumophila, PEC suspensions were washed three times with RPMI medium by centrifugation at $1500 \mathrm{rpm}$ for $5 \mathrm{~min}$ to remove non-internalised legionellae. The packed cells were lysed by addition of sterile distilled water and kept at room temperature for $30 \mathrm{~min}$. The lysates were centrifuged as above to eliminate cell debris, the supernates were plated on BCYE- $\alpha$ agar, and the number of intracellular bacteria was determined as cfu.

\section{Microscopy}

Suspensions of washed PEC were distributed on to multi-spot slides, carefully air dried and fixed by depositing a small amount of iced $\left(-80^{\circ} \mathrm{C}\right)$ methanol on each spot. DFA staining was performed by standard methods. Preparations were observed under UV light with a SM-Lux Leitz microscope. The three-dimensional localisation of legionellae within the cells was observed with a confocal laser scanning microscope (Phoibos 1000, Serastro Inc., Ypsilanti MI, USA).

\section{RT-PCR analysis of TNF $\alpha$ mRNA expression in $P E C$ of suckling mice}

The reverse-transcriptase polymerase chain reaction (RT-PCR) was used to detect tumour necrosis factor (TNF- $\alpha$ ) mRNA produced in mice challenged with L. pneumophila. Groups of 15-30 mice were inoculated with the two different $L$. pneumophila strains, as described above; an equal number of mice were inoculated with diluent alone as a control group. After $24 \mathrm{~h}$, PEC were collected from mice by peritoneal washing with RPMI $(0.5 \mathrm{ml} /$ mouse $)$ and total cellular RNA was extracted from PEC as described by Chomczynski and Sacchi [25]. Potential contaminating DNA was digested with DNAase $(10 \mathrm{U} / \mu 1,15 \mathrm{~min}$, $37^{\circ} \mathrm{C}$ ). The final RNA pellet was resuspended in
RNAase-free $\mathrm{H}_{2} \mathrm{O}$ and reverse-transcribed for $60 \mathrm{~min}$ at $37^{\circ} \mathrm{C}$ in a $20-\mu 1$ reaction mixture composed of oligo (dT 12-18) (Pharmacia, Uppsala, Sweden) $0.1 \mu \mathrm{g} / \mathrm{ml}$, Moloney murine leukaemia virus reverse transcriptase (Gibco BRL, Sauthersburg, MD, USA) $20 \mathrm{U}$ and $20 \mathrm{mM}$ dithiothreitol in Moloney murine leukaemia virus reverse transcriptase buffer (Gibco BRL).

cDNAs obtained by this procedure were amplified by PCR in the presence of specific primer pairs for murine TNF- $\alpha$ or $\beta$-actin gene sequences. $5^{\prime}$ and $3^{\prime}$ primer pairs were synthesised by Pharmacia (Uppsala, Sweden) with the following sequences: $\beta$-actin: TCCTGTGGCATCCACGAAACTE and GAAGCATTTGCGGTGGACGAT; TNF- $\alpha$ : CTCCAGCITGGAAGACTCCTCCCAG and GATCTCAAAGACAACCAACTAGTG.

PCR mixtures contained $0.05 \mu \mathrm{M}$ of $5^{\prime}$ and $3^{\prime}$ primers, $2 \mathrm{mM}$ deoxynucleotides, and $0.5 \mathrm{U}$ of AmpliTaq polymerase in gene Amp PCR buffer (Gene-Amp Kit; Perkin-Elmer, Norwalk, CO, USA), in a total volume of $20 \mu \mathrm{l}$. The reaction was conducted in a Perkin-Elmer thermal cycler for 30 cycles $(40 \mathrm{~s}$ of denaturation at $94^{\circ} \mathrm{C}, 40 \mathrm{~s}$ of annealing at $62^{\circ} \mathrm{C}$ and $1 \mathrm{~min}$ extension at $72^{\circ} \mathrm{C}$ ).

PCR products were visualised by agarose electrophoresis; Hae III-digested $\phi x 174$ DNA (Gibco BRL) was run in parallel as the mol.-wt markers. PCR products were identified by their predicted molecular mass.

For semi-quantitative measurements of TNF- $\alpha$ mRNA, serial five-fold dilutions of cDNA samples were subjected to PCR amplification of the $\beta$-actin gene sequence; the amount of the resulting PCR product was quantified with a Pharmacia LKB Ultroscan XL densitometer and plotted as a function of the input template cDNA to construct linear curves. For the comparative analysis of TNF- $\alpha$ mRNA expression by PEC of different groups of mice, dilutions of cDNA were normalised with these curves so as to yield an equivalent intensity of $\beta$-actin signal in all samples.

\section{Statistical analysis}

Mortality differences among the various groups of $L$. pneumophila-infected mice were assessed for their statistical significance by the Mann-Whitney $U$ test or the Fisher's exact test, as appropriate.

\section{Results}

\section{Preliminary infections in adult and newborn mice}

Preliminary infections of suckling mice by i.n. or i.p. routes with L. pneumophila strain Corby and an isolate of L. pneumophila from a patient with Legionnaires' disease either fresh (Monza 3) or after 50 passages in subculture (Monza 3p50) showed elevated mortality 
after i.n. infection, with no difference among the strains. In contrast, mice inoculated i.p. with the serially passaged strain showed a significantly lower mortality than did mice inoculated with the original parent strain. In fact, MST and $\mathrm{D} / \mathrm{T}$ ratio of animals inoculated with $3 \times 10^{7}$ cells of strains Monza 3 and Monza $3 \mathrm{p} 50$ were 1 day and 6/6, 15 days and $1 / 7$, respectively.

When animals of different age were examined for their resistance to a challenge with the Monza 3 strain, the results clearly showed a progressive decrease in susceptibility to infection, and no mouse older than 1 month was killed by an inoculum as high as $3 \times 10^{8}$ bacterial cells (Table 1 ).

Viable Legionella cells were needed for lethal infection of suckling mice, as shown by the total lack of animal mortality following inoculation of up to $3 \times 10^{8}$ heat-killed or sonicated cells (data not shown). Equal amounts of viable or sonicated cells of both Monza 3 and Monza 3p50 strains gave similar positive results in the Limulus endotoxin assay.

Experimental infection of guinea-pigs confirmed the loss of the apparent 'virulence' of L. pneumophila strain Monza 3p50. In fact, groups of four animals inoculated i.p. with graded cellular suspensions up to

Table 1. Age dependence susceptibility of Swiss CD1 mice to intraperitoneal injection of $L$. pneumophila strain Monza 3 (serogroup 6)

\begin{tabular}{llc}
\hline Age of mice (days) & D/T $(\%)$ & MST (days) \\
\hline $0-16$ & $7 / 8(87.5)$ & 3 \\
$17-19$ & $4 / 8(50.0)$ & 4 \\
$20-26$ & $1 / 8(12.5)^{*}$ & $>15^{*}$ \\
$30-35$ & $0 / 10(0.0)^{*}$ & $\ldots$ \\
$60^{\dagger}$ & $0 / 10(0.0)$ & $\ldots$ \\
\hline
\end{tabular}

The inoculum comprised $6.5 \times 10^{7}$ cells; MST, median survival time; D/T, dead over total animals within 15 days of observation. *Statistically significant difference $(p<0.01)$ between the indicated values and the $D / T$ value of 0 -16-day-old mice (as assessed by Fisher's exact test) or the MST value of either the $0-16$ or the 1719-day-old animals (as assessed by the Mann-Whitney U test).

${ }^{\dagger}$ Inoculated with $3 \times 10^{8}$ L. pneumophila cells.
$10^{9} \mathrm{cfu}$ of the strain Monza 3 showed an inoculum size-dependent mortality that reached $100 \%$, while those receiving the same numbers of Monza $3 \mathrm{p} 50$ cells showed a $100 \%$ survival and no signs of illness during the 15 days of observation. Notably, the strain Monza 3p50 did not regain the ability to kill either the suckling mice or the guinea pigs after four in-vivo passages in suckling mice.

On the basis of these data, suckling mice aged 5-7 days were used in all further experiments and strains Monza 3 and Monza 3p50 were conventionally defined as virulent and avirulent strains of L. pneumophila, respectively.

\section{Virulence variations of different L. pneumophila strains}

Several L. pneumophila strains were compared for their virulence in the suckling mouse model. No significant differences were detected among strains of the different serogroups examined, provided that they were freshly isolated from human sources. All of them caused $c$. $50 \%$ mortality and an MST ranging from 1 to 5 days after inoculation of $(1-3) \times 10^{7}$ cells. The two environmental isolates of $L$. pneumophila were apparently less lethal than human isolates (see the MST values in Table 2).

\section{Clearance of L. pneumophila by suckling mice}

Mice were examined for the persistence of $L$. pneumophila in their organs after i.p. challenge with the virulent or the avirulent strain. As shown in Table 3 , spleen and liver of three mice randomly taken from the different groups yielded a high number of legionellae $5 \mathrm{~h}$ after inoculation with either the virulent or the avirulent strain, and this trend was generally apparent at $24 \mathrm{~h}$. Seven days after infection, more legionellae of the avirulent strain than of the virulent one were recovered from the above organs. In contrast, more legionellae were recovered from the lungs of mice infected with the virulent strain than from the lungs of those inoculated with the avirulent strain, even

Table 2. Mortality of suckling mice after intraperitoneal inoculation with fresh isolates of L. pneumophila

\begin{tabular}{|c|c|c|c|c|c|c|c|}
\hline \multirow{2}{*}{\multicolumn{2}{|c|}{$\begin{array}{l}\text { Strain } \\
\text { (serogroup) }\end{array}$}} & \multirow{2}{*}{$\begin{array}{l}\text { MAb } \\
\text { subtype* }\end{array}$} & \multirow[b]{2}{*}{ Origin } & \multicolumn{2}{|c|}{ Mortality $\left(1 \times 10^{7}\right.$ cells $/$ mouse $)$} & \multicolumn{2}{|c|}{ Mortality $\left(3 \times 10^{7}\right.$ cells $/$ mouse $)$} \\
\hline & & & & $\mathrm{D} / \mathrm{T}$ & MST (days) & $\mathrm{D} / \mathrm{T}$ & MST (days) \\
\hline Monza 3 & (6) & $\ldots$ & Human & $5 / 10$ & 3 & $6 / 6$ & 1 \\
\hline Messina 2 & (3) & $\ldots$ & Human & $6 / 10$ & 1 & ND & ND \\
\hline Trento 1 & (1) & Pontiac & Human & $5 / 6$ & 2 & $4 / 4$ & 2 \\
\hline Trento 2 & (1) & Pontiac & Human & $3 / 6$ & 5 & $8 / 8$ & 1 \\
\hline Trento 3 & (1) & Pontiac & Environment & $3 / 11$ & $>30^{\dagger}$ & $5 / 8$ & 2 \\
\hline Roma 9 & (14) & $\ldots$ & Human & $2 / 5$ & $>30^{\dagger}$ & $\mathrm{ND}^{\ddagger}$ & $\mathrm{ND}^{\ddagger}$ \\
\hline Forio 4 & (1) & Olda & Environment & ND & ND & $5 / 9$ & $7^{\dagger}$ \\
\hline
\end{tabular}

$\mathrm{D} / \mathrm{T}$, dead/total; MST, median survival time; ND, not done.

* Of the Oxford L. pneumophila serogroup 1 monoclonal subtyping scheme.

†Statistically significant $(\mathrm{p}<0.01$ ) difference between the indicated values and those of all other groups as assessed by the Mann-Whitney $U$ test.

${ }^{\ddagger}$ After an inoculum of $2.2 \times 10^{7}$, D/T was $6 / 10$, MST was 3 . 
Table 3. Number of legionellae isolated from organs of suckling mice at various time intervals after injection of $L$. pneumophila Monza 3 and Monza 3p50 strains

\begin{tabular}{|c|c|c|c|c|c|}
\hline \multirow[b]{2}{*}{ Strain } & \multirow{2}{*}{$\begin{array}{l}\text { Inoculum size } \\
\text { (cells) }\end{array}$} & \multirow[b]{2}{*}{ Time points } & \multicolumn{3}{|c|}{$\mathrm{cfu}(\mathrm{SEM}), 10^{3}$, recovered from } \\
\hline & & & Lung & Spleen & Liver \\
\hline Monza 3 & $3 \times 10^{7}$ & $\begin{array}{l}5 \mathrm{~h} \\
24 \mathrm{~h} \\
7 \text { days }\end{array}$ & $\begin{array}{l}331(38.5) \\
328(16.75) \\
50.57(16.45)\end{array}$ & $\begin{array}{c}566.6(23.4) \\
985(16.23) \\
3.85(2.97)\end{array}$ & $\begin{array}{c}2900(64.9) \\
845.2(32.6) \\
31.39(8.28)\end{array}$ \\
\hline Monza 3p50 & $1.5 \times 10^{7}$ & $\begin{array}{l}5 \mathrm{~h} \\
24 \mathrm{~h} \\
7 \text { days } \\
14 \text { days }\end{array}$ & $\begin{array}{l}27.6(10.8) \\
2.8(2.16) \\
3.22(3.5) \\
2.5(5.4)\end{array}$ & $\begin{array}{l}633.2(9.7) \\
193.6(16.76) \\
239(13.11) \\
61.74(19.95)\end{array}$ & $\begin{array}{c}2764.8(127.2) \\
66.8(8.52) \\
167.6(26.18) \\
62.88(6.3)\end{array}$ \\
\hline Monza 3p50 & $6 \times 10^{7}$ & $\begin{array}{l}5 \mathrm{~h} \\
24 \mathrm{~h} \\
7 \text { days }\end{array}$ & $\begin{array}{l}26.6(9.95) \\
15.87(5.38) \\
3.26(3.04)\end{array}$ & $\begin{array}{c}1062.4(27.84) \\
1071.5(47.8) \\
465(15.35)\end{array}$ & $\begin{array}{c}2155.1(52.94) \\
680.4(44.46) \\
148.2(17.5)\end{array}$ \\
\hline
\end{tabular}

Numbers represent legionellae isolated from pools of single organs of three mice randomly taken from four litters (Monza 3) or two and three litters Monza 3p50. Mice inoculated with the virulent strain and killed on day 7 had survived the infection.

at a higher inoculum. The difference equalled or was even greater than one order of magnitude (Table 3 ). Overall, in these experiments, of the 42 mice (from four litters) infected with Monza 3 strain (inoculum $3 \times 10^{7}$ cells), eight died within $24 \mathrm{~h}$, and 26 died 48 $72 \mathrm{~h}$ after the challenge. None of the 50 mice (five litters) inoculated with the Monza $3 \mathrm{p} 50$ (inocula $1.5 \times 10^{7}$ and $6 \times 10^{7}$ cells) died during 15 days of observation.

Avirulent L. pneumophila was cleared slowly from the total body of the animals and high numbers of microbial cells (c. $10^{4}$ cells/whole animal) were present for at least 3 weeks. However, no legionellae were isolated from 1-month-old mice (data not shown).

\section{Presence of L. pneumophila in peritoneal macrophages of suckling mice}

Because of the characteristic intramacrophage localisation of L. pneumophila $[16,26]$, the presence of the micro-organism in the PEC of suckling mice was examined, and for comparison, in those of adult mice.

The presence of L. pneumophila in suckling mice was demonstrated by immunofluorescence and confocal microscopy. At $24-48 \mathrm{~h}$ after challenge with the virulent strain, some $\mathrm{M} \phi$ contained numerous legionellae within a cytoplasmic vesicle, others appeared completely overwhelmed by the micro-organism (Fig. 1). After infection with the avirulent derivative, fewer $M \phi$ appeared to be infected and few legionellae were seen within each infected cell (Fig. 1). Confocal micrographs of PEC from suckling mice taken at different levels of the peritoneal cells showed intracellular legionellae (Fig. 2).

L. pneumophila cfu counts demonstrated roughly equal numbers of total PEC-associated microbial cells, but it should be remembered that the virulent strain induced a much greater PEC recruitment in the peritoneal cavity than the avirulent strain (about $1 \log _{10}$ difference $6 \mathrm{~h}$ after infection) (data not shown).

A similar pattern of intramacrophage localisation of the two Legionella strains was observed in PEC from adult mice $24-48 \mathrm{~h}$ after infection. Five and 10 days after infection the macrophages of adult mice showed fragments and a speckled appearance of immunofluorescence, probably due to digested bacteria.

\section{TNF- $\alpha$ mRNA expression in PEC of suckling mice infected by L. pneumophila}

Because L. pneumophila is known to induce of TNF- $\alpha$ production by both human and murine $\mathrm{M} \phi[27,28]$, TNF- $\alpha$ production by PEC of suckling mice challenged by either the virulent or the avirulent $L$. pneumophila strain was examined. In preliminary experiments, cytokine production was assayed both in the peritoneal fluid (as protein, by ELISA) and in PEC (as mRNA transcript by RT-PCR). As very low and inconsistent amounts of TNF- $\alpha$ were detected in the peritoneal fluid, all subsequent experiments addressed TNF- $\alpha$ mRNA production. As shown in Fig. 3, a strong TNF- $\alpha$ mRNA signal was detected in mice infected with $L$. pneumophila Monza 3, contrasting with a very weak signal in animals infected with Monza 3 p50, and no signal at all in mice given the diluent only (negative control). Densitometric measurements of TNF- $\alpha$ message (expressed as density ratio between TNF- $\alpha$ and $\beta$ actin mRNA signals) gave the following results: 1.40 versus 0.30 (first experiment) and 0.70 versus 0.10 (second experiment) for mice challenged with Monza 3 and Monza 3p50, respectively, thus indicating 5-7-fold greater TNF- $\alpha$ mRNA production in mice challenged with the virulent strain.

\section{Discussion}

In-vivo studies aimed at evaluating bacterial virulence are essential to unravel host-parasite relationships. In the context of the virulence of Legionella strains for 

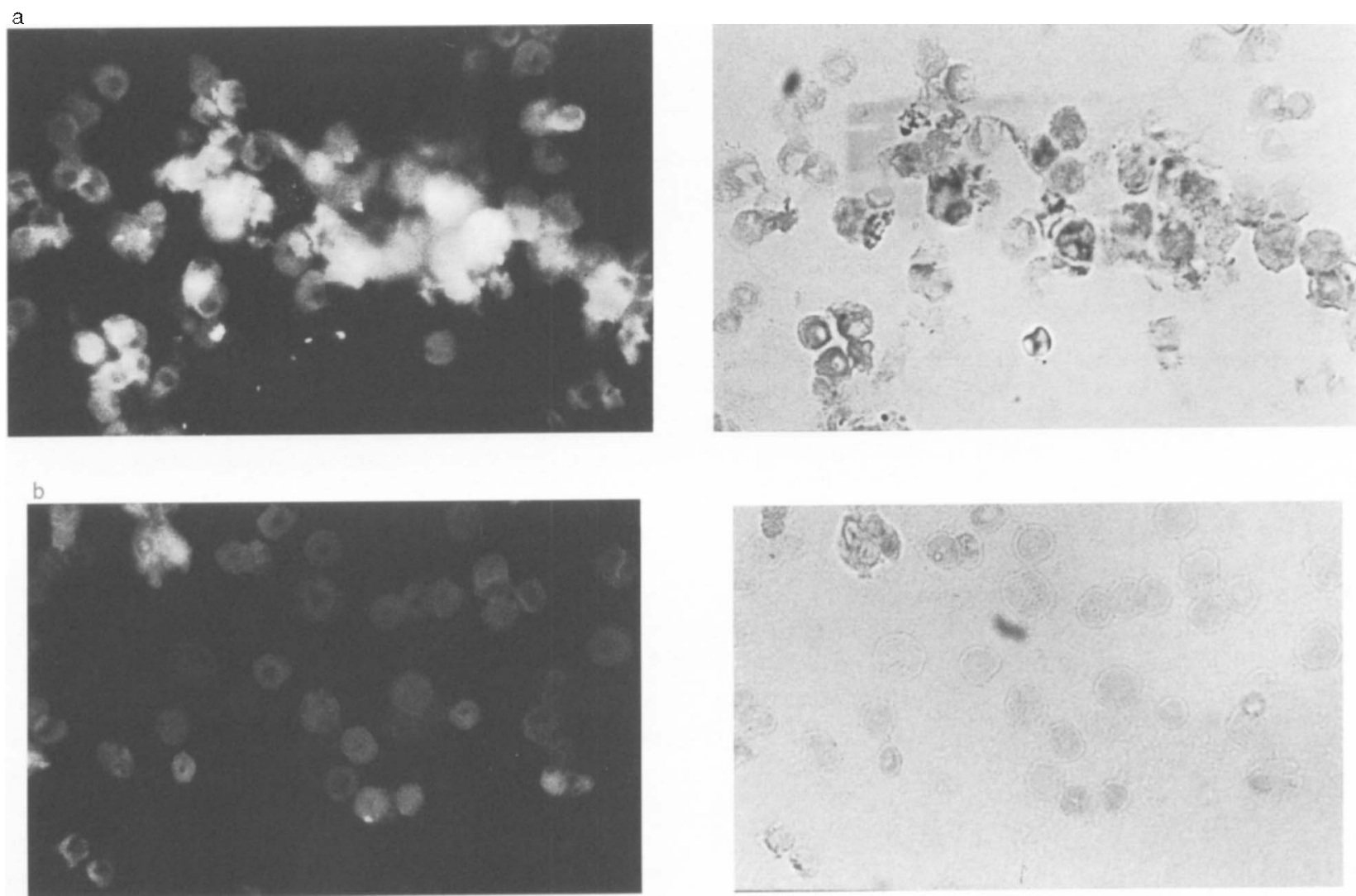

Fig. 1. Peritoneal exudate cells (PEC) from Swiss CD1 suckling mice infected with L. pneumophila, stained by direct immunofluorescence $48 \mathrm{~h}$ after infection. Fluorescence (left) and light (right) micrographs show the same microscopic fields. a, PEC infected with the virulent $L$. pneumophila strain Monza 3: some cells exhibit numerous fluorescent bacteria, others appear to be completely engulfed. b, PEC infected with the avirulent derivative Monza 3p50: few cells appear to be infected and few legionellae are seen within the cells. Magnification $\times 570$.

a

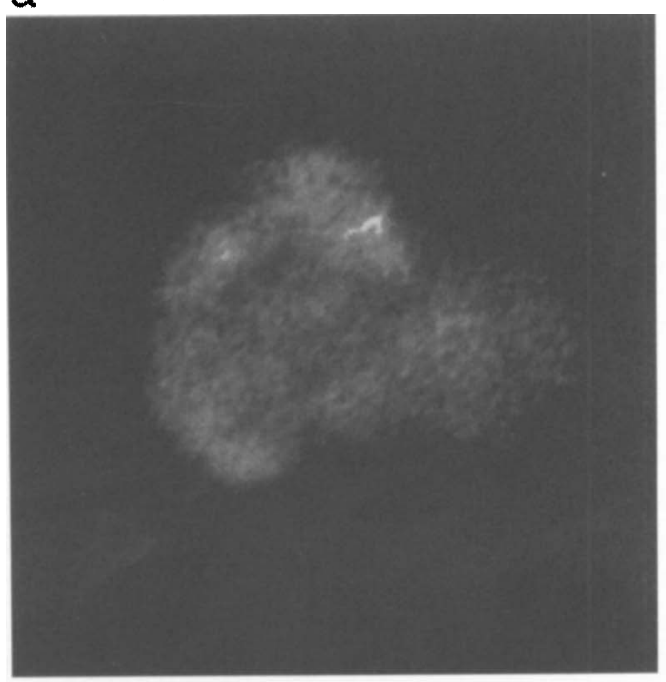

b

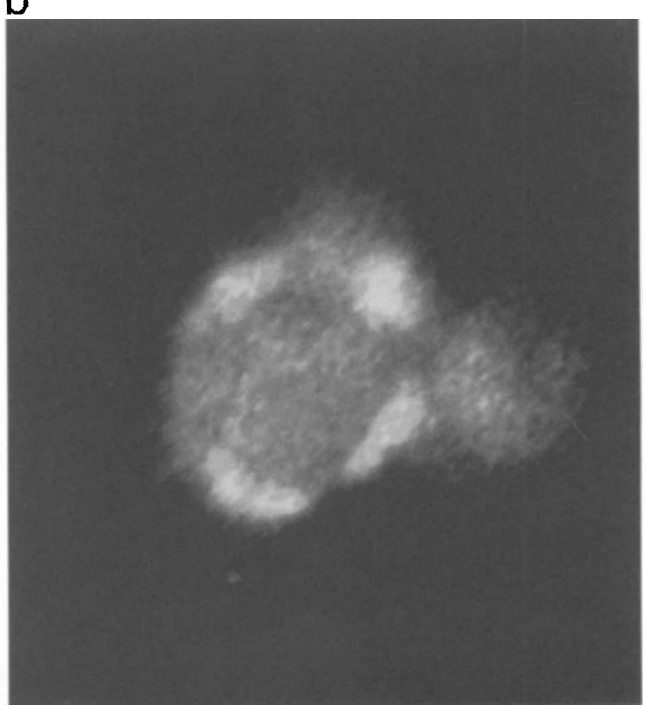

Fig. 2. Peritoneal monocytic cell from Swiss CD1 suckling mouse infected with the virulent L. pneumophila strain Monza 3, stained by direct immunofluorescence. Confocal scanning micrographs taken at different levels of the cell: a, tangential to the cell membrane; b, cross-sectional to cell nuclear substance, showing intracellular legionellae. Magnification $\times 2350$.

normal laboratory animals, only guinea-pigs have so far been demonstrated to be suitable experimental models [15]. However, these animals are not easily amenable to immunological investigations. Normal adult mice are usually highly resistant to experimental legionellosis $[15,16,29]$, even though immunocompromised mice $[4,7,17,19]$ and the genetically susceptible $\mathrm{A} / \mathrm{J}$ mice $[18,30]$ have been shown to support growth of 


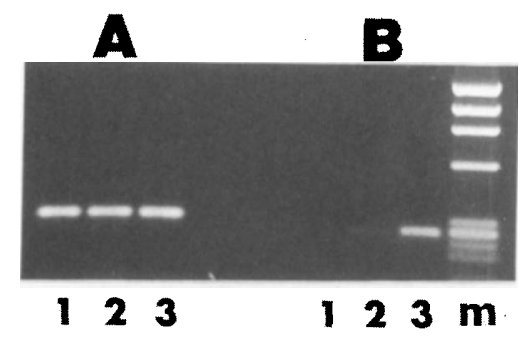

Fig. 3. TNF- $\alpha$ gene expression by PEC of mice infected with $L$. pneumophila. Three groups of 10 mice were inoculated with diluent alone (1) or with L. pneumophila, avirulent (2) or virulent strain (3). Dilution of cDNA samples was adjusted so as to yield equivalent amounts of $\beta$-actin PCR product (A). After $24 \mathrm{~h}$, total mRNA was extracted from PEC and TNF- $\alpha$ gene expression (B) was analysed by semi-quantitative RT-PCR, as described in Materials and methods. m, mol.-wt markers.

legionellae in the lung, particularly after intra-tracheal infection [31]. L. pneumophila replicates well in humans and guinea-pigs $M \phi$ as well as in those of $\mathrm{A} / \mathrm{J}$ mice $[29,32-35]$. Growth is limited in $\mathrm{M} \phi$ from other mouse species, while it is supported by those of golden hamster and rat, although these animals are resistant to infection [29]. In general, there is conflicting evidence about replication in mouse $\mathrm{M} \phi$ and, more generally, on the relative validity of inhalatory versus non-inhalatory routes of infection in mimicking, at least in part, human disease $[11,36]$.

On the assumption that adult mouse resistance to $L$. pneumophila could be due to the development of the immune system, and that host defences are lower in infant animals, the susceptibility of suckling mice to infection was studied, with the main purpose of verifying whether the model adopted could be suitable and sensitive enough to detect virulence differences among isolates of L. pneumophila.

These studies indicate that suckling CD1 mice are susceptible to lethal i.p. challenge with viable $L$. pneumophila strains of fresh clinical isolation, but not with those from long-maintained and repeatedly passaged cultures, in keeping with the observed low mortality rate after inoculation into mice of laboratory strains from stock cultures. However, it was also observed that i.n. inoculation of mice with $L$. pneumophila brought about an elevated mortality regardless of the type of the strain used for challenge. It is difficult to explain why virulence differences are not evidenced by i.n. infection but are shown by i.p. infection.

Hedlund and co-workers [17] demonstrated replication of legionellae only in the spleen of adult AKR/J susceptible mice challenged i.p. with as high as $2 \times 10^{8}$ virulent legionellae. The histopathology of the liver of infected animals was suggestive of toxic or anoxic damage rather than bacterial infection. Hedlund [37] also reported the death of animals infected with a cell-free sonicate of legionellae. In the present study, the death of CD1 suckling mice after i.p. inoculation required viable legionellae, as high inocula of heat-inactivated cells $\left(>10^{8}\right)$ or sonicates of $L$. pneumophila cultures were totally ineffective. Endotoxin production appears not to be involved, as the Limulus test was equally positive for suspensions of both virulent and avirulent L. pneumophila strains, and for the crude toxin, but all mice inoculated with the filtrate from $c .3 \times 10^{8}$ sonicated legionellae survived.

The basis for virulence differences, as detected in the described animal model, are unknown. It should be stressed here that the above model cannot be considered as truly representative of a reproductive infection by $L$. pneumophila. Given the high inoculum used for infection, what was essentially measured was a difference in the rate of clearance of the legionellae by the mouse. However, the above difference appears to be a sensible correlate of virulence, as it was stably reproduced in different experiments, required viable L. pneumophila cells and was also observed in control experiments with guinea-pigs, which are ordinarily susceptible to $L$. pneumophila infection. In this context, a potentially relevant observation is that the virulent $L$. pneumophila strain is less rapidly cleared from lungs (but not from liver and spleen) than the avirulent strain. It would be important in future studies to assess alveolar $\mathrm{M} \phi$ of suckling and adult mice for intracellular growth permissiveness of strains Monza 3 and Monza 3p50. PEC of suckling mice were found to be more heavily parasitised by Monza 3 than by Monza $3 p 50$ cells. Whether this implies some permissiveness of the $\mathrm{M} \phi$ of these animals to intracellular growth of $L$. pneumophila cannot be stated at the moment. However, the data would indicate that, in contrast to $\mathrm{M} \phi$ of adult mice, those of the infant mice take up and internalise the virulent strain to a greater extent than the avirulent strain or (alternatively or concurrently) they kill the latter more efficiently than the former.

Relevant to this is the fact that L. pneumophila may exert a direct toxic effect on host cells without necessarily invading or multiplying in them [38]. As pro-inflammatory cytokines, in particular TNF- $\alpha$, are strongly induced by legionellae [27], TNF- $\alpha$ production by PEC of animals challenged with virulent or avirulent strain was investigated. TNF- $\alpha$ mRNA was found to be expressed more in PEC from mice challenged with the former strain, although this could not be confirmed by the actual cytokine detection in the peritoneal fluid (probably because of its low quantity or rapid binding, neutralisation or degradation). It is possible that - together with the production of other toxic shock-related cytokines, such as, for instance, IL-1 $\beta$ [39] - TNF- $\alpha$ production could rapidly bring the animal to toxic shock and death. TNF- $\alpha$ is currently considered to be an important 
factor facilitating the resolution of $L$. pneumophila infection [40] but, as in other biological situations, localised and rapid induction of this cytokine in a newborn animal may also exert an intense toxic effect and cachexia [41].

Although no specific virulence factor or mechanism has been sought in this study, these results suggest that suckling CD1 mice are a promising, easily handled and inexpensive animal model for studies of Legionella virulence. With this model, virulence of fresh clinical isolates of L. pneumophila was demonstrated, and seen to be attenuated or even totally lost after repeated subcultures on artificial media, a classic biological parameter of bacterial virulence attenuation. Interestingly, virulence was accompanied by a longer persistence of a greater burden of legionellae in the lungs, and a greater capacity for stimulating TNF- $\alpha$ production in the peritoneal cavity, both observations being potentially relevant to human pathology. Finally, the model showed a very low variability in the susceptibility of different litters of mice and thus has good reproducibility. Studies are in progress to determine specific virulence factors of Legionella spp. and modulation of the host cytokine response in mouse organs.

This work was supported in part by grants 94.02850. CT04 and 95.01663.CT04 from the Italian National Research Council (CNR, Consiglio Nazionale delle Ricerche). We are grateful to Dr R. B. Fitzgeorge, CAMR, Porton Down, for providing the Legionella strain Corby. We also thank Dr D. D'Urso for the confocal micrographs; Elisabetta Volpi and Cinzia Reda for technical support; Mr R. Filippi for enthusiastic and careful animal supervision; and Anna Maria Marella, Francesca Baschieri and Francesca Girolamo for assistance in the preparation of the manuscript.

These data were presented in part at the 1992 International Symposium on Legionella, Orlando, FA, and the 6th European Congress of Clinical Microbiology and Infectious Diseases, 1993, Seville, Spain.

\section{References}

1. Fraser DW. Sources of legionellosis. In: Thornsberry C, Balows A, Feeley JC, Jakubowski W (eds) Legionella, Proceedings of the 2nd International Symposium. Washington, DC, American Society for Microbiology. 1984: 277-280.

2. McDade JE, Shepard CC, Fraser DW et al. and the Laboratory Investigation Team. Isolation of a bacterium and demonstration of its role in other respiratory disease. N Engl J Med 1977; 297: $1197-1203$.

3. Arko RJ, Wong $\mathrm{KH}$, Feeley JC. Immunologic factors affecting the in vivo and in-vitro survival of the Legionnaires' disease bacterium. Ann Intern Med 1979; 90: 680-683.

4. Drutz DJ, De Marsh P, Edelstein P et al. Legionella pneumophila pneumonia in athymic nude mice. In: Thornsberry C, Balows A, Feeley JC, Jakubowski W (eds) Legionella, Proceedings of the 2nd International Symposium. Washington, DC, American Society for Microbiology. 1984: 134-135.

5. Eisenstein TK, Friedman H. Immunity to Legionella. In: Katz SM (ed) Legionellosis, 2nd edn, Boca Raton, FL, CRC Press. 1985: 159-169.

6. Saravolatz LD, Burch $\mathrm{KH}$, Fisher E et al. The compromised host and Legionnaires' disease. Ann Intern Med 1979; 90: 533-537.

7. Widen R, Klein T, Friedman H. Enhanced susceptibility of cyclophosphamide-treated mice to infection with Legionella pneumophila. J Infect Dis 1984; 149: 1023-1024.
8. Yamamoto Y, Klein TW, Friedman H. Legionella pneumophila intracellular growth in normal vs. immune guinea pigs macrophages cultures. Curr Microbiol 1988; 16: 333-336.

9. Dreyfus LA. Virulence associated ingestion of Legionella pneumophila by HeLa cells. Microb Pathog 1987; 3: 45-52.

10. Fields BS, Barbaree JM, Shotts EB et al. Comparison of guinea-pig and protozoan models for determining virulence of Legionella species. Infect Immun 1986; 53: 553-559.

11. Fitzgeorge RB, Baskerville A, Broster M, Hambleton P, Dennis PJ. Aerosol infection of animals with strains of Legionella pneumophila of different virulence: comparison with intraperitoneal and intranasal routes of infection. $J$ Hyg 1983; 90: $81-89$.

12. Jepras RI, Fitzgeorge RB, Baskerville A. A comparison of virulence of two strains of Legionella pneumophila based on experimental aerosol infection of guinea-pigs. J Hyg 1985; 95 : 29-38.

13. Pearlman E, Jiwa AH, Engleberg NC, Eisenstein BI. Growth of Legionella pneumophila in a human macrophage-like (U937) cell line. Microb Pathog 1988; 5: 87-95.

14. Baskerville A, Dowsett AB, Fitzgeorge RB, Hambleton P, Broster M. Ultrastructure of pulmonary alveoli and macrophages in experimental Legionnaires' disease. J Pathol 1983; 140: $77-90$.

15. Collins MT. Legionella infections in animals. Isr J Med Sci 1986; 22: 662-673.

16. Davis GS, Winn WC, Gump DW, Craighead JE, Beaty HN. Legionnaires' pneumonia after aerosol exposure in guinea pigs and rats. Am Rev Respir Dis 1982; 126: 1050-1057.

17. Hedlund KW, McGann VG, Copeland DS, Little SF, Allen RG. Immunologic protection against the Legionnaires' disease bacterium in the AKR/J mouse. Ann Intern Med 1979; 90: $676-679$.

18. Yamamoto Y, Klein TW, Newton CA, Widen R, Friedman H. Growth of Legionella pneumophila in thioglycollate-elicited peritoneal macrophages from A/J mice. Infect Immun 1988; 56: $370-375$.

19. Blanchard DK, Friedman H, Stewart WE, Klein TW, Djeu JY. Role of gamma interferon in induction of natural killer activity by Legionella pneumophila "in vitro" and in an experimental murine infection model. Infect Immun 1988; 56: 1187-1193.

20. Castellani Pastoris M, Volpi E. Susceptibility of suckling mice to intraperitoneal challenge with Legionella pneumophila. 1992 International Symposium on Legionella. Orlando, FL, 26-29 January, 1992. p. 12. Abstract nos. 1-5.

21. Castellani Pastoris M, Proietti E, Volpi E, D'Urso D. Suckling mouse as a suitable experimental animal model for Legionella infection studies. 6th European Congress of Clinical Microbiology and Infectious Diseases. Seville, Spain, 28-31 March, 1993. Book of abstracts p. 205. Abstract no. 809.

22. Edelstein PH. Improved semiselective medium for isolation of Legionella pneumophila from contaminated clinical and environmental specimens. $J$ Clin Microbiol 1981; 14: 298-303.

23. Dennis PJ, Bartlett CLR, Wright AE. Comparison of isolation methods for Legionella spp. In: Thornsberry C, Balows A, Feeley JC Jakubowski W (eds) Legionella, Proceedings of the 2nd International Symposium. Washington, DC, American Society for Microbiology. 1984: 294-296.

24. Watkins ID, Tobin JO'H, Dennis PJ, Brown W, Newnham R, Kurtz, JB. Legionella pneumophila serogroup 1 subgrouping by monoclonal antibodies - an epidemiological tool. $J$ Hyg 1985; 95: $211-216$.

25. Chomczynski P, Sacchi N. Single-step method of RNA isolation by acid guanidinium thiocyanate-phenol-chloroform extraction. Anal Biochem 1987; 162: 156-159.

26. Blackmon JA, Hicklin MD, Chandler FW. Legionnaires' disease. Pathological and historical aspects of a 'new' disease. Arch Pathol Lab Med 1978; 102: 337-343.

27. Blanchard DK, Djeu JY, Klein TW, Friedman H, Stewart WE. Induction of tumor necrosis factor by Legionella pneumophila. Infect Immun 1987; 55: 433-437.

28. Matsiota-Bernard $P$, Léfèbre $C$, Sedqui $M$, Cornillet $P$, Guenounou M. Involvement of tumor necrosis factor alpha in intracellular multiplication of Legionella pneumophila in human monocytes. Infect Immun 1993; 61: 4980-4983.

29. Yoshida S, Mizuguchi Y. Multiplication of Legionella pneumophila Philadelphia-1 in cultured peritoneal macrophages and its correlation to susceptibility of animals. Can J Microbiol 
1986; 32: 438-442.

30. Yamamoto Y, Klein TW, Friedman H. Legionella pneumophila growth in macrophages from susceptible mice is genetically controlled. Proc Soc Exp Biol Med 1991; 196: 405-409.

31. Brieland J, Freeman P, Kunkel R et al. Replicative Legionella pneumophila lung infection in intratracheally inoculated $\mathrm{A} / \mathrm{J}$ mice. A murine model of human Legionnaires' disease. $\mathrm{Am} J$ Pathol 1994; 145: $1537-1546$

32. Horwitz MA, Silverstein SC. Legionnaires' disease bacterium (Legionella pneumophila) multiplies intracellularly in human monocytes. J Clin Invest 1980; 66: 441-450.

33. Kishimoto RA, White JD, Shirey FG et al. In-vitro response of guinea pig peritoneal macrophages to Legionella pneumophila. Infect Immun 1981; 31: 1209-1213.

34. Yamamoto Y, Klein TW, Newton CA, Friedman H. Interaction of Legionella pneumophila with peritoneal macrophages from various mouse strains. Adv Exp Med Biol 1988; 239: 89-98.

35. Wright JB, Rechnitzer C, Kharazmi A, Sorensen BA, Bertelsen TB. Guinea pig alveolar macrophage function during the course of a sublethal Legionella pneumophila infection. Immun
Infect Dis 1993; 3: 181-187.

36. Friedman H, Klein TW, Widen R, Newton C, Blanchard DK, Yamamoto Y. Legionella pneumophila immunity and immunomodulation: nature and mechanisms. Adv Exp Med Biol 1988; 239: $327-341$.

37. Hedlund KW. Legionella toxin. Pharmacol Ther 1981; 15 $123-130$.

38. Husmann LK, Johnson, W. Cytotoxicity of extracellular Legionella pneumophila. Infect Immun 1994; 62: 2111-2114.

39. Klein TW, Yamamoto Y, Wilson S, Newton C, Friedman H. Legionella pneumophila infection and cytokine production. $A d v$ Exp Med Biol 1992; 319: 97-104.

40. Brieland JK, Remick DG, Freeman PT, Hurley MC, Fantone $\mathrm{JC}$, Engleberg NC. In vivo regulation of replicative Legionella pneumophila lung infection by endogenous tumor necrosis factor alpha and nitric oxide. Infect Immun 1995; 63: 3253-3258.

41. Beutler B, Cerami A. Cachectin and tumour necrosis factor as two sides of the same biological coin. Nature 1986; 320: 584-588. 